\title{
Simulasi Springback pada Laser Beam Bending dan Rotary Draw Bending untuk Pipa AISI 304L
}

\author{
Adnan Syadidan, Mas Irfan P. Hidayat, dan Wikan Jatimurti \\ Departemen Teknik Material, Fakultas Teknologi Industri, Institut Teknologi Sepuluh Nopember (ITS) \\ e-mail:irfan@mat-eng.its.ac.id
}

\begin{abstract}
Abstrak-Proses bending tube pada dewasa ini telah mengalami banyak perkembangan. Dua metode diantaranya adalah rotary draw bending yang bersifat konvensional serta laser beam bending yang lebih modern. Selain itu, untuk mengoptimalkan proses tube bending diperlukan pengertian lebih mendalam terhadap fenomena springback, agar hasil yang didapatkan lebih presisi. Pada penelitian ini dilakukan analisis springback menggunakan Finite Element Method dengan bantuan software ANS YS 17.1. Simulasi dilakukan untuk mendapatkan hasil springback dari kedua metode yang nantinya akan dibandingkan. Penelitian pertama dilakukan dengan mensimulasikan proses laser beam bending hingga mencapai batas maksimum sudut bending yang dapat diterima. Selain itu, simulasi juga dilakukan pada metode rotary draw bending dengan parameter diameter dan ketebalan tube yang sama seperti sebelumnya namun, dengan sudut bending yang berbeda yaitu sebesar 60, 120, dan 180 yang akan digunakan sebagai data pendukung nilai springback. Dari simulasi didapatkan bahwa semakin tinggi laser power dan pass number pada laser beam bending, maka akan semakin tinggi springback yang dihasilkan namun, masih sangat kecil bila dibangdingkan dengan rotary draw bending.
\end{abstract}

Kata Kunci-Springback, 304L, Rotary Draw Bending, Laser Beam Bending, Metode Elemen Hingga.

\section{PENDAHULUAN}

$\mathrm{T}$ UBE bending merupakan hal yang sangat penting dalam industri manufaktur sebagai contoh pada boiler, mesin, heat exchanger, pendingin ruangan, dan pipa maupun tube. Tubes dapat dibengkokkan secara mekanis baik dalam keadaan panas (hot bending) maupun dingin (cold bending), walaupun proses bending lebih banyak digunakan dalam keadaan dingin. Cold bending lebih efisien dan menghasilkan produk yang lebih rigid, sedangkan hot bending lebih sesuai untuk sudut bending yang lebih kecil atau diameter tube yang lebih besar. [1]

Laser forming merupakan teknik forming dengan proses bebas springback dan juga tanpa kontak yang dalam dekade belakangan telah banyak dilakukan penelitian tentangnya. Dibandingkan dengan mengaplikasikan gaya eksternal menggunakan tools forming, laser forming lebih disebabkan oleh deformasi plastis yang dihasilkan dari tegangan termal akibat pemanasan laser dan pendinginan yang cepat. Meskipun asal mula dari laser forming dapat ditelusuri dari metode flame bending yang telah ada sebelumnya, namun laser forming memiliki teknik yang lebih mulus dan terkendali yang menawarkan banyak kemungkinan aplikasi unik.
Berbagai kemungkinan aplikasi ini dihasilkan dari kontrol yang baik pada transfer energi, akurasi tingkat tinggi dan reproduktifitas, fleksibilitas yang tinggi, serta sifat tanpa kontaknya.[2]

Rotary draw bending merupakan proses fisik tri-nonlinier dengan efek kopling multifactor dan beberapa kecacatan seperti local wrinkling, over thinning (bahkan crack), dan distorsi cross-section dengan parameter forming yang tidak sesuai. Bila dibandingkan dengan proses bending yang lain, metode ini merupakan proses kontak dominan dalam multidie constraints dengan menggunakan bend die, clamp die, pressure die, wiper die, serta mandrel (dengan mandrel shank dan bola fleksibel). [3] Hanya dengan penggunaan yang presisi dari alat-alat ini, memungkinkan kestabilan dan ketepatan dari deformasi bending dapat dicapai dengan $\mathrm{Rd} / \mathrm{D}$, bebas wrinkling, derajat deformasi dari wall thinning dan cross-section. Gesekkan dari berbagai interfaces alat memungkinkan untuk memberikan efek yang berbeda-beda dari perilaku deformasi bending metode ini.[4]

Sedangkan springback merupakan fenomena strain recovery yang diakibatkan pelepasan tegangan sisa pada lembaran logam saat dilepaskan dari cetakan. Dalam rangka memprediksi besar nilai dari springback, simulasi akurat dari tegangan pada dead point dan perilaku tanpa beban dari material sangat dibutuhkan. Penelitian springback secara teoritis dan eksperimental pada rotary draw telah banyak dilakukan. Hasil dari penelitian tersebut menunjukkan bahwa sudut springback berbanding lurus dengan sudut bending pada sudut bending yang besar, dan kontrol bend-rebend biasanya mengandung data springback dan penyeimbangnya. Metode dari kontrol proses dikembangkan untuk mengoptimalkan strategi kontrol secara keseluruhan. Prediksi springback berdasarkan eksperimen dianggap cukup terpercaya, mengandung data springback yang hanya berlaku pada tube bending dengan kondisi yang sama.[1]

\section{METODE PENELITIAN}

\section{A. Peralatan yang Digunakan}

Peralatan yang digunakan dalam penelitian berupa perangkat lunak (software) berbasis metode elemen hingga yaitu ANSYS dengan modul Mechanical APDL Release 17.1 yang digunakan untuk membuat pemodelan springback dan memodelkan simulasi metode rotary draw bending dan laser beam bending.

\section{B. Material Tube}

Pada penelitian ini, material yang digunakan pada proses tube bending adalah AISI 304L. Data material yang ada diperoleh dari North American Stainless dengan 
menggunakan standar UNS S30430, EN 1.4307 dan ASM Handbook Vol 1. Komposisi dari AISI 304L dapat dilihat pada Tabel 1 dan untuk properti material AISI 304L dapat dilihat pada Tabel 2 berikut.

Tabel 1.

Standar Komposisi Kimia AISI 304L (NAS-UNS S30430, EN 1.4307)

\begin{tabular}{cccccccc}
\hline \hline Unsur & $\mathrm{C}$ & $\mathrm{Mn}$ & $\mathrm{P}$ & $\mathrm{S}$ & $\mathrm{Si}$ & $\mathrm{Cr}$ & $\mathrm{Ni}$ \\
\hline Min & & & & & & 18.00 & 8.00 \\
Max & 0.03 & 2.0 & 0.045 & 0.030 & 1.00 & 20.00 & 12.00 \\
\hline \hline
\end{tabular}

Tabel 2.

Properti Material dari AISI 304L

\begin{tabular}{c|c}
\hline \hline Konduktivitas $(\mathrm{W} / \mathrm{m} \mathrm{K})$ & 31.7 \\
Specific Heat $(\mathrm{J} / \mathrm{kg} \mathrm{K})$ & 682 \\
Koefisien Konveksi $\left(\mathrm{W} / \mathrm{m}^{2}\right)$ & 20 \\
Poisson ratio & 0.3 \\
Modulus Elastisitas $(\mathrm{Gpa})$ & 196 \\
Density $\left(\mathrm{kg} / \mathrm{m}^{3}\right)$ & 7850 \\
Thermal Expansion $(1 / \mathrm{K})$ & $2.00 \mathrm{E}-5$ \\
\hline \hline
\end{tabular}

\section{Geometri Tube}

Geometri yang digunakan kedua metode bending pada penelitian ini yaitu tube berpenampang lingkaran. Penampang lingkaran ini memiliki ukuran outer diameter sebesar $15 \mathrm{~mm}$ dengan ketebalan tube $2 \mathrm{~mm}$. Kedua metode memiliki panjang yang sama yaitu $800 \mathrm{~mm}$.

\section{Pemodelan Pipa}

Tipe pemodelan yang digunakan pada penelitian ini untuk kedua metode menggunakan element type SHELL 132 dengan 8 nodes untuk analisa termal dan SHELL281 dengan 8 nodes untuk analisa struktural, dengan satu derajat kebebasan (DOF) temperatur pada masing masing nodes. Pada metode laser beam bending digunakan dua analisa yaitu termal dan struktural. Properti material yang dimasukkan untuk analisa termal antara lain konduktivitas termal isotropic, specific heat, densitas, serta koefisien konveksi, lalu untuk analisa structural antara lain poisson ratio, modulus elastisitas, serta densitas. Adapun pemodelan boundary condition pada laser beam bending untuk analis a termal, perpindahan panas yang terjadi adalah konveksi, dimana konveksi terjadi pada semua permukaan tube kecuali pada daerah yang dikenai laser, konveksi yang terjadi merupakan free convection artinya konveksi tanpa ada pengaruh dari luar. Proses adiabatik dianggap terjadi pada tube path yang dikenai sinar laser. Untuk analisa structural, salah satu sisi tube akan dijepit ke segala arah, sehingga dapat dilihat respon mekanik yang terjadi. Sedangkan untuk die pada rotary draw bending dianggap rigid.

\section{E. Meshing}

Meshing yang digunakan pada simulasi laser beam bending dan rotary draw bending menggunakan metode free mesh dengan elemen segitiga dan smartsize 1 untuk tube. Elemen segitiga dipilih karena mempermudah memperoleh konvergensi namun diperlukan meshing dengan ukuran yang cukup halus

\section{F. Tipe Pembebanan}

Pembebanan pada penelitian kali ini dibagi berdasarkan tipe pembebanan untuk masing-masing metode. Untuk tipe pembebanan metode laser beam bending yaitu pembebanan termal. Pada proses termal, tube akan diberi panas yang berasal dari laser dalam bentuk heatflux, melintang pada tengah sisi kiri tube selama 10 detik. Setelah proses pemanasan selesai, maka dilakukan proses pendinginan dengan free convection selama 180 detik. Proses pemanasan dan pendinginan ini dilakukan selama dua kali (2 pass) untuk mendapatkan hasil distribusi temperatur. Nilai distribusi temperature ini kemudian akan menjadi pembebanan struktural yang akan ditambahkan dengan beban displacement pada sisi kanan tube sebesar 0 sebagai boundary condition. Langkah ini akan diulang kembali untuk jumlah pass serta laser power lainnya. Sedangkan tipe pembebanan pada metode rotary draw bending, menggunakan displacement ke arah sumbu Z (ROTZ) dengan menggunakan pilot node pada bend die, dan pressure pada tube dengan nilai internal pressure $=5$.

Pembebanan pada metode laser beam bending dilakukan hingga mencapai sudut tertentu yang merupakan batas maksimal kemampuannya bila tanpa adanya external pressure. Hal ini dikarenakan metode laser beam bending memiliki keterbatasan sudut bending yang besarannya akan dicari pada percobaan kali ini. Hasil analisa struktur dari metode laser beam bending ini nantinya akan dibandingkan dengan metode rotary draw bending. Seluruh variasi pembebanan akan dijelaskan di dalam Tabel 3 di bawah ini.

Tabel 3 .

Variasi Pembebanan pada Percobaan

\begin{tabular}{cc}
\hline \hline Laser Power $(\mathrm{W})$ & Pass Number \\
\hline \multirow{2}{*}{900} & 2 pass \\
& 3 pass \\
& 4 pass \\
\hline \multirow{2}{*}{1200} & 2 pass \\
& 3 pass \\
& 4 pass \\
\hline \multirow{2}{*}{1500} & 2 pass \\
& 3 pass \\
\end{tabular}

\section{G. Tipe Analisa}

Proses analisa yang digunakan untuk kedua metode adalah analisa springback, yang didapat dari nilai displacement. Selain itu, analisa tegangan Von Mises juga dapat digunakan untuk menganalisa ada tidaknya pelepas an tegangan sebagai tanda akan terjadinya springback. Adapun perbandingan masing-masing metode bending pada percobaan ini dijelaskan dalam Tabel 4 di bawah ini.

Tabel 4.

Perbandingan Metode Proses Penelitian

\begin{tabular}{ccc}
\hline \hline Metode & Pembebanan & Analisa \\
\hline Laser Beam & Termal & $\begin{array}{c}\text { Sudut } \\
\text { bending dan } \\
\text { Bending }\end{array}$ \\
Rpringback \\
Betary Draw & Displacement dan & Springback \\
\hline \hline
\end{tabular}




\section{HASIL DAN DISKUSI}

Untuk menentukan jumlah springback, maka simulasi tegangan yang akurat dilakukan dengan memberikan suatu beban dalam jangka waktu tertentu kemudian mengamati perilaku unloading dari logam tersebut. Analisa springback pada penelitian laser beam bending kali ini dilakukan dengan cara mengamati perubahan displacement dan juga von mises stress pada saat proses pelepasan beban terakhir untuk setiap pass. Adapun untuk analisa springback pada metode rotary draw bending diamati pada saat proses pelepasan beban setelah bending.

Pemodelan analisa springback untuk metode laser beam bending dimulai dengan membuat desain tube. Pada tube kemudian diberikan heatflux. Setelah melakukan pengaturan pada software yang digunakan maka dilakukan proses solving. Hasil yang didapat dari simulasi adalah perpindahan yang terjadi serta nilai von misses stress-nya. Hasil ini belum memperlihatkan springback yang muncul. Untuk mendapatkan springback-nya dilakukan proses penghilangan beban dari benda kerja dengan cara pendinginan menggunakan konveksi. Mekanisme pendinginan inilah yang memunculkan springback pada proses ini.

\section{A. Pengamatan Hasil Pemodelan Laser Beam Bending}

Berdasarkan penelitian yang telah dilakukan di atas maka, dapat dilihat bahwa sudut bending maksimum yang dapat dicapai menggunakan metode laser beam bending bila dilakukan tanpa adanya beban struktural dari luar adalah sebesar $0,01221^{\circ}$ serta terjadi pada variasi laser power sebesar $1500 \mathrm{~W}$ dengan pass number sebanyak 3 pass. Hal ini menjelaskan bahwa ketika ingin menambah kemampuan sudut bending pada laser beam bending dapat dilakukan dengan cara menambah jumlah laser power dari metode tersebut. Adapun nilai selisih sudut bending pada 3 pass untuk setiap laser power adalah $0,002407^{\circ}$ untuk laser power antara $1200 \mathrm{~W}$ dengan $900 \mathrm{~W}$ serta $0,002465^{\circ}$ untuk laser power antara $1500 \mathrm{~W}$ dengan $1200 \mathrm{~W}$.

Sedangkan, nilai hasil springback mencapai angka terbesar untuk metode laser beam bending adalah pada saat laser power $1500 \mathrm{~W} 3$ pass sebesar $0,006363^{\circ}$. Adapun nilai selisih springbak pada 3 pass untuk setiap laser power adalah $0,001239^{\circ}$ untuk laser power antara $1200 \mathrm{~W}$ dengan $900 \mathrm{~W}$ serta $0,001295^{\circ}$ untuk laser power antara $1500 \mathrm{~W}$ dengan $1200 \mathrm{~W}$. Hal ini menunjukkan, semakin tinggi input dari laser power maka akan semakin tinggi pula sudut bending serta springback yang dapat dicapai pada metode laser beam bending ini.

Namun, anomali terjadi pada saat variasi laser 4 pass dilakukan di mana springback yang muncul tidaklah menuju ke arah negatif bending namun, menuju ke arah positif dari sudut bending awal yang dicapai. Anomali ini pun terjadi pada saat kondisi penghilangan beban termal terjadi atau pada saat cooling condition. Adapun perbandingan hasil sudut bending dan springback berdasarkan tiap power laser dan pass number dijelaskan pada Gambar 1 dan Gambar 2 berikut.

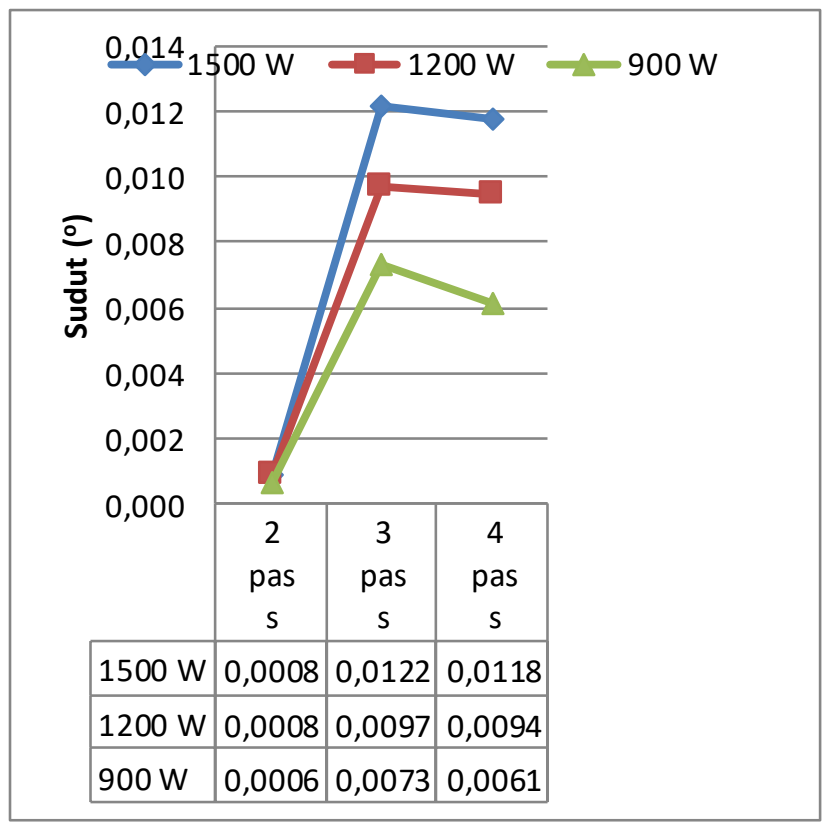

Gambar 1. Grafik Perbandingan Hasil Sudut Bending untuk Setiap Laser Power dan Pass Number

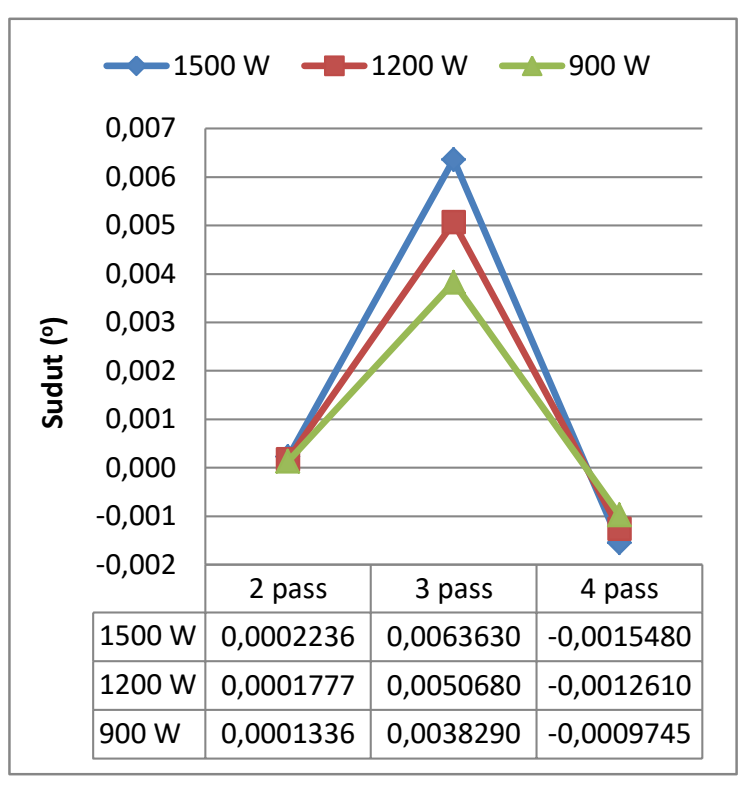

Gambar 2. Grafik Perbandingan Hasil Springback untuk Setiap Laser Power dan Pass Number

\section{B. Hasil Pengujian Struktur Mikro pada Hammer Crusher}

Perbedaan yang muncul dari hasil penelitian ini terhadap kedua metode diantaranya adalah kemampuan sudut bending, radius bending, profil bending, springback yang dihasilkan, serta perubahan energi yang terjadi. Telah ditunjukkan pada analisa data di atas bahwa metode rotary draw bending memiliki kemampuan sudut bending yang lebih besar dan baik bila dibandingkan dengan metode laser beam bending. Hal ini dapat dilihat pada Tabel 5 yang merupakan perbandingan kemampuan sudut bending untuk metode laser beam bending dan rotery draw bending. Perbandingan yang digunakan untuk metode laser beam bending hanya pada kemampuan sudut maksimum berdasarkan penelitian ini yaitu proses bending pada 3 pass untuk setiap laser power. 
Tabel 5.

Perbandingan Kemampuan Sudut Bending Penelitian pada Metode Laser Beam Bending dan Rotary Draw Bending

\begin{tabular}{cccc}
\hline \hline \multicolumn{3}{c}{ Laser Beam Bending } & $\begin{array}{c}\text { Rotary Draw } \\
\text { Bending }\end{array}$ \\
\hline $900 \mathrm{~W}$ & $1200 \mathrm{~W}$ & $1500 \mathrm{~W}$ & $180^{\circ}$ \\
\hline $0,1221^{\circ}$ & $0,009745^{\circ}$ & $0,007338^{\circ}$ & 100 \\
\hline \hline
\end{tabular}

Begitupun dengan radius bending yang dapat dicapai oleh metode laser beam bending yang memiliki keterbatasan bila dibandingan dengan metode rotary draw bending. Profil bending pada metode rotary draw bending pun terlihat lebih halus bila dibandingkan dengan metode laser beam bending. Namun, springback yang dihasilkan oleh metode laser beam bending sangat jauh lebih kecil dibandingkan dengan metode rotary draw bending. Hal ini lah yang menjadi kelebihan dari metode laser beam bending sehingga kedepannya metode ini sangat banyak mengalami pengembangan seperti penggunaan die dan external force untuk menanggulangi kekurangan-kekurangan yang telah dijelaskan. Adapun perbandingan springback yang muncul pada kedua metode akan dijelaskan pada Tabel 6 dan Tabel 7 berikut.

Tabel 6.

Perbandingan Hasil Springback Penelitian pada Metode Laser Beam Bending

\begin{tabular}{cccc}
\hline \multicolumn{4}{c}{ Laser Beam Bending } \\
\hline & $900 \mathrm{~W}$ & $1200 \mathrm{~W}$ & $1500 \mathrm{~W}$ \\
\hline Sudut & $6,48 \mathrm{E}-4^{\circ}$ & $8,66 \mathrm{E}-4^{\circ}$ & $8,6 \mathrm{E}-4^{\circ}$ \\
2 pass & $1,34 \mathrm{E}-4^{\circ}$ & $1,78 \mathrm{E}-4^{\circ}$ & $2,24 \mathrm{E}-4^{\circ}$ \\
Sudut & $7,34 \mathrm{E}-3^{\circ}$ & $9,75 \mathrm{E}-3^{\circ}$ & $1,22 \mathrm{E}-2^{\circ}$ \\
3 pass & $3,83 \mathrm{E}-3^{\circ}$ & $5,07 \mathrm{E}-3^{\circ}$ & $6,36 \mathrm{E}-3^{\circ}$ \\
Sudut & $6,14 \mathrm{E}-3^{\circ}$ & $9,46 \mathrm{E}-3^{\circ}$ & $1,18 \mathrm{E}-2^{\circ}$ \\
4 pass & $-9,8 \mathrm{E}-4^{\circ}$ & $-1,26 \mathrm{E}-3^{\circ}$ & $-1,54 \mathrm{E}-3^{\circ}$ \\
\hline \hline
\end{tabular}

Tabel 7.

Perbandingan Hasil Springback Penelitian pada Metode Rotary Draw Bending

\begin{tabular}{cccc}
\hline \hline \multicolumn{4}{c}{ Rotary Draw Bending } \\
\hline Sudut bending & $60^{\circ}$ & $120^{\circ}$ & $180^{\circ}$ \\
Springback & $1,54^{\circ}$ & $2,469^{\circ}$ & $3,11^{\circ}$ \\
\hline \hline
\end{tabular}

Adapun perubahan energi yang terjadi pada saat loading maupun unloading untuk kedua metode mengalami perbedaan. Perbedaan pertama yaitu berupa besarnya energi yang muncul. Pada metode laser beam bending dapat terlihat energi terbesar yang muncul hanya mencapai angka 0,4366 MPa. angka ini sangatlah kecil bila dibandingkan dengan metode rotary draw bending yang mampu menghasilkan energi maksimum hingga mencapai $397 \mathrm{MPa}$. Hal ini membuktikan bahwa metode leser beam bending memiliki efisiensi penghematan energi yang lebih baik untuk dapat digunakan kedepannya. Perbedaan kedua yaitu mengenai energi yang muncul pada saat unloading. Seperti yang diketahui bersama bahwa springback merupakan suatu kejadian yang mengindikasikan stress relief yang muncul pada saat unloading dari proses bending. Teori ini terbukti pada metode rotary draw bending sebagai mana terlihat di atas. Namun, hal ini tidaklah terjadi pada metode laser beam bending. Pada metode laser beam bending, springback yang terjadi malah menghasilkan penambahan energi yang muncul pada daerah bending dari tube, terutama pada daerah buckling dari tube itu sendiri setelah unloading. Hal ini dapat terjadi dikarenakan springback yang muncul pada metode laser beam bending didasari oleh mekanisme pemuaian dan penyusutan secara pengamatan macro di mana, apabila diamati secara micro maka mekanisme ini disebabkan oleh perubahan fasa yang terjadi selama pemanasan dan pendinginan. Perubahan fasa yang terjadi juga menyebabkan perubahan bentuk dan struktur kristal penyusunnya sehingga menimbulkan perubahan dislokasi. Perubahan dislokasi ini lah yang akhirnya menciptakan residual stress terpusat yang memunculkan indikasi peningkatan energi pada springback dan bukan memunculkan stress relief. Berikut adalah Tabel 8 dan Tabel 9 mengenai perbandingan energi yang muncul pada saat kondisi loading dan unloading.

Tabel 8.

Perbandingan Energi pada Kondisi Loading

\begin{tabular}{|c|c|c|c|}
\hline \multicolumn{4}{|c|}{ Laser Beam Bending } \\
\hline & $900 \mathrm{~W}$ & $1200 \mathrm{~W}$ & $1500 \mathrm{~W}$ \\
\hline 2 pass & $24820,4 \mathrm{~Pa}$ & $33093,8 \mathrm{~Pa}$ & $41367,3 \mathrm{~Pa}$ \\
\hline 3 pass & $247776 \mathrm{~Pa}$ & $330368 \mathrm{~Pa}$ & $412960 \mathrm{~Pa}$ \\
\hline 4 pass & $260680 \mathrm{~Pa}$ & $347574 \mathrm{~Pa}$ & $434467 \mathrm{~Pa}$ \\
\hline \multicolumn{4}{|c|}{ Rotary Draw Bending } \\
\hline & $60^{\circ}$ & $120^{\circ}$ & $180^{\circ}$ \\
\hline & $395 \times 10^{6} \mathrm{~Pa}$ & $395 \times 10^{6} \mathrm{~Pa}$ & $397 \times 10^{6} \mathrm{~Pa}$ \\
\hline
\end{tabular}

Tabel 9.

Perbandingan Energi pada Kondisi Unloading

\begin{tabular}{|c|c|c|c|}
\hline \multicolumn{4}{|c|}{ Laser Beam Bending } \\
\hline & $900 \mathrm{~W}$ & $1200 \mathrm{~W}$ & $1500 \mathrm{~W}$ \\
\hline 2 pass & $25393,2 \mathrm{~Pa}$ & $33857,6 \mathrm{~Pa}$ & $42322 \mathrm{~Pa}$ \\
\hline 3 pass & $253926 \mathrm{~Pa}$ & $338568 \mathrm{~Pa}$ & $423210 \mathrm{~Pa}$ \\
\hline 4 pass & $261932 \mathrm{~Pa}$ & $349243 \mathrm{~Pa}$ & $436554 \mathrm{~Pa}$ \\
\hline \multicolumn{4}{|c|}{ Rotary Draw Bending } \\
\hline & $60^{\circ}$ & $120^{\circ}$ & $180^{\circ}$ \\
\hline & $209 \times 10^{6} \mathrm{~Pa}$ & $208 \times 10^{6} \mathrm{~Pa}$ & $206 \times 10^{6} \mathrm{~Pa}$ \\
\hline
\end{tabular}

\section{KESIMPULAN}

1. Semakin besar laser power yang diberikan pada metode laser beam bending maka semakin tinggi pula springback yang dihasilkan untuk tube berpenampang lingkaran dengan OD $15 \mathrm{~mm}$ dan tebal $2 \mathrm{~mm}$ material SS304L.

2. Semakin banyak pass number yang diberikan pada metode laser beam bending maka semakin tinggi pula springback yang dihasilkan untuk tube berpenampang lingkaran dengan OD $15 \mathrm{~mm}$ dan tebal $2 \mathrm{~mm}$ material SS304L.

3. Springback yang dihasilkan oleh proses bending untuk tube berpenampang lingkaran dengan OD $15 \mathrm{~mm}$ 
dan tebal $2 \mathrm{~mm}$ material SS304L menggunakan metode laser beam bending lebih kecil bila dibandingkan dengan proses bending bila dilakukan menggunakan metode rotary draw bending.

\section{UCAPAN TERIMA KASIH}

Penulis mengucapkan terima kasih seluruh pihak yang telah mendukung penelitian kali ini.

\section{DAFTAR PUSTAKA}

[1] S. et al Sumikawa, "Improvement of Springback Prediction Accuracy by Considering Nonlinear Elastoplastic Behavior After Stress Reversal," 2017.

[2] L. Hao, N. dan Li, "An Analytical Model For Laser Tube Bending," 2003.

[3] S. Thorat, "Finite Element Analysis and Mathematical Calculation of Springback in Rotary Draw Tube Bending," 2015.

[4] dan M. Z. Yang, H., H. Li, "Friction Role in Bending Behaviors of Thin-Walled Tube in Rotary-Draw-Bending Under Small Bending Radii,” 2010. 